\title{
A Novel Liquid Packaging Structure of Deep-Ultraviolet Light-Emitting Diodes to Enhance the Light-Extraction Efficiency
}

\author{
Chieh-Yu Kang ${ }^{1}$, Chih-Hao Lin ${ }^{1}{ }^{(\mathbb{C}}$, Tingzhu Wu ${ }^{2, *} \mathbb{C}$, Po-Tsung Lee ${ }^{1}$, Zhong Chen ${ }^{2}$ and \\ Hao-Chung Kuo ${ }^{1 \text {,* }}$ \\ 1 Department of Photonics and Institute of Electro-Optical Engineering, College of Electrical and Computer \\ Engineering, National Chiao Tung University, Hsinchu 30010, Taiwan; kangcy1026@gmail.com (C.-Y.K.); \\ actupon@gmail.com (C.-H.L.); potsung@mail.nctu.edu.tw (P.-T.L.) \\ 2 Department of Electronic Science, Fujian Engineering Research Center for Solid-State Lighting, \\ Xiamen University, Xiamen 361005, China; chenz@xmu.edu.cn \\ * Correspondence: wutingzhu@xmu.edu.cn (T.W.); hckuo@faculty.nctu.edu.tw (H.-C.K.); \\ Tel.: +886-35712121-31986 (H.-C.K.)
}

Received: 1 March 2019; Accepted: 4 April 2019; Published: 12 April 2019

\begin{abstract}
To realize high-efficiency, AlGaN-based, deep-ultraviolet light-emitting diodes (DUV-LEDs), enhancing their light-extraction efficiency and reducing thermal resistance is very crucial. We proposed a liquid packaging structure that could enhance optical power by $27.2 \%$ and $70.7 \%$ for flat type and lens type 281-nm DUV-LEDs, respectively. A significant improvement effect at different wavelengths, such as $268 \mathrm{~nm}$ and $310 \mathrm{~nm}$, was also observed. Furthermore, using the liquid packaging structure, the thermal resistance was reduced by $30.3 \%$ compared to the conventional structure. Finally, the reliability of liquid packaging DUV-LEDs was tested. The light output maintenance of liquid packaging DUV-LEDs was compared to the conventional structure.
\end{abstract}

Keywords: deep-ultraviolet light emitting diode; silicone oil; liquid packaging

\section{Introduction}

Deep-ultraviolet light emitting diodes (DUV-LEDs) have been attracting significant attention as a new light source that can replace conventional mercury-based UV lamps in disinfection, chemical decomposition, water and air purification, and food safety control [1-3]. Compared to mercury-based UV lamps, DUV-LEDs have more advantageous characteristics, including small volume, easy integration, a long life-time, tunable wavelength, and being mercury-free [2,4]. However, the light efficiency and output power of DUV-LED devices are still low. The highest reported external quantum efficiency (EQE) and power output in the ultraviolet C (UVC) range (200-290 nm) is $14.3 \%$ and $153.4 \mathrm{~mW}$, respectively [2,4-8]. On the other hand, the mainstream design of DUV-LED packages uses quartz glass as the cover without an encapsulation material inside the cavity [9]. This kind of package structure reduces the light extraction severely and limits the optical performance of DUV-LEDs [10,11]. To ameliorate these drawbacks, some DUV transparency encapsulation materials have been proposed for the DUV-LED package structure [12-14].

In this study, a liquid packaging structure for DUV-LEDs was developed. The light output was enhanced by $70.7 \%$ compared to the conventional package structure. Furthermore, the thermal resistance of the liquid packaging structure for DUV-LEDs was measured. Using the liquid packaging structure, the thermal resistance was reduced by $30.3 \%$ compared to the conventional structure. The reliability of liquid packaging DUV-LEDs was also tested. The light output maintenance of liquid packaging DUV-LEDs for 200 hours remained above $98 \%$. 


\section{Materials and Methods}

The Figure 1 illustrates the structures of five different package types (PTs): PT-I is a DUV-LED without a quartz plate, PT-II denotes a conventional flat type DUV-LED, PT-III stands for a conventional lens type DUV-LED, PT-IV is a flat type liquid packaging DUV-LED, and PT-V denotes the lens-type liquid packaging DUV-LED proposed in this study. In Figure 1, the black part is the DUV-LED chip. The blue part is the ceramic substrate with an Au coating. The green part is a quartz cover that has a flat type and lens type. The pink part is silicone oil in the cavity substrate. All the structures are composed of the same chip and ceramic substrate. For the DUV-LED chip, its output power and peak wavelength in the ceramic substrate was about $9.30 \mathrm{~mW}$ and $281 \mathrm{~nm}$ at $60 \mathrm{~mA}$, respectively. The chip size was $250 \times 500 \times 200 \mu \mathrm{m}$. The chip structure was the flip chip type, so we use a refractive index of sapphire of about 1.82 in the UVC range [15] as the light source. The material of the cavity substrate was aluminium nitride and its size was $3.5 \times 3.5 \mathrm{~mm}$. A thin film of gold with a reflectance of $38 \%$ was plated on the bottom and the top of the cavity. The sidewall was AlN with 16\% reflectance. There were two types of quartz plate placed on the top of the substrate. One was flat type and the other was lens type. The size of the flat type quartz plate and lens type quartz plate were $3.3 \times 3.3 \times 0.5 \mathrm{~mm}$ and $3.3 \times 3.3 \times 1.7 \mathrm{~mm}$.

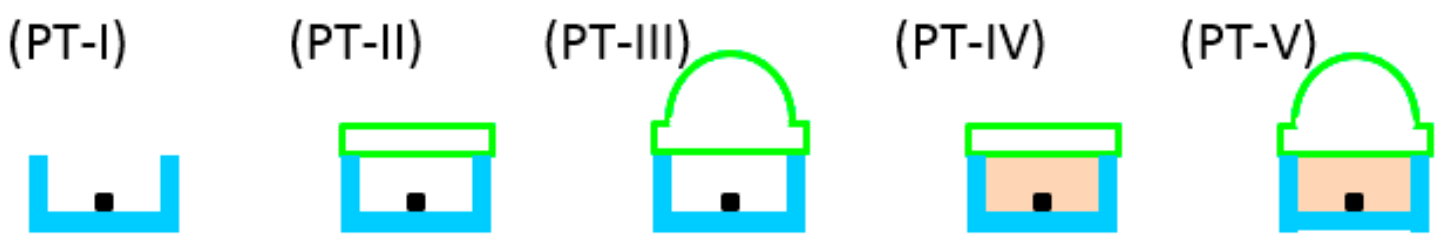

Figure 1. Structure diagrams of the five package types of the Deep-ultraviolet light emitting diodes (DUV-LEDs).

The silicone oil we used in this study was dimethylpolysiloxane, with the part number KF-96-50CS (Shin-Etsu Chemical Co., Ltd, Tokyo, Japan). Its refractive index was 1.487 [16] in the UVC range and its transmission spectrum, shown in Figure 2, was measured by spectrophotometer (model name: U2900, Hitachi, Tokyo, Japan). The result shows that the transmittance of the silicone oil was over $82 \%$ from $260 \mathrm{~nm}$ to $350 \mathrm{~nm}$. The structure of silicone oil is very simple, it is composed of Si-O and Si-CH functional groups. The main chain of silicone oil is bonded by Si-O, which has a high bonding energy of $108 \mathrm{Kcal} / \mathrm{mol}$. It is not easily broken by UVC and ultraviolet B (UVB) (290-320 nm), since UVC and UVB energy is $102 \mathrm{Kcal} / \mathrm{mol}$ and $91 \mathrm{Kcal} / \mathrm{mol}$, respectively. This characteristic makes silicone oil transparent from 260 to $350 \mathrm{~nm}$. In commercial silicone, due to its solid property, some $\mathrm{CH}_{2}$ functional groups will be added to the main structure to make the main chains longer and the molecular weight higher. When $\mathrm{CH}_{2}$ functional groups are in the main chain, $\mathrm{C}-\mathrm{C}$ bonds occur, which have a low bonding energy of $85 \mathrm{Kcal} / \mathrm{mol}$. In addition, some additivities like the phenyl group, UV absorber and hardener are added to the commercial silicone. These additivities will reduce the transmittance in the deep-UV range. In Figure 2, we also added the transmission spectrum of the commercial silicone Dow corning, OE66 series, for comparison in the deep UV region. The high transmittance of this wavelength range ( $260 \mathrm{~nm}$ to $350 \mathrm{~nm}$ ) of silicone oil is very useful for deep-UV LED packages, since most recent investigations and applications of deep-UV LED are in this wavelength range $[1,2,17,18]$. For $281 \mathrm{~nm}$, the transmittance of silicone oil is about $94 \%$. 


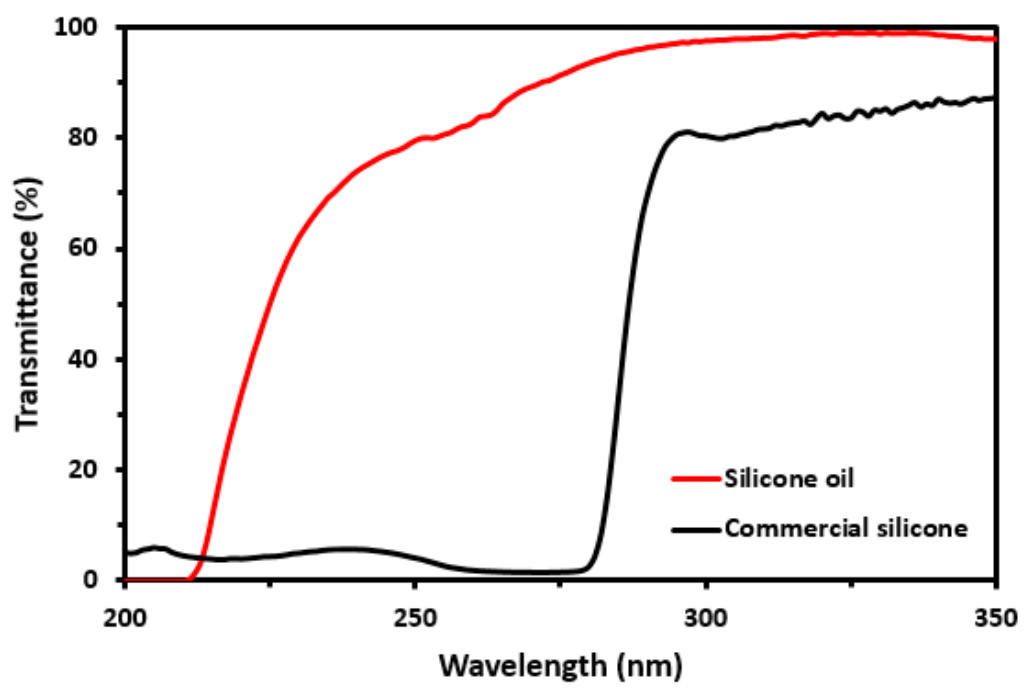

Figure 2. Transmittance of silicone oil.

A ray-tracing simulation was performed using Light Tools ${ }^{\mathrm{TM}}$ (Synopsys Inc, Mountain View City, CA, USA). Table 1 lists all the optical parameters of the ray-tracing simulation. The simulation 3D model is shown in Figure $3 a$ and the simulation result is shown from Figure $3 b-f$. In Figure 3b, the ray-tracing profile for PT-I DUV-LEDs demonstrates that the color of chip part is black, which means that the DUV light (for $281 \mathrm{~nm}$ ) was trapped inside the DUV chip and only $42.9 \%$ of light can exit the DUV chip due to the total internal reflection (TIR) loss resulting from the large refractive index gap between sapphire (the top of DUV chip, $\mathrm{n}=1.82)$ and air $(\mathrm{n}=1)$. After the light exits the chip, the light will be absorbed by a ceramic reflector and the light output is reduced to $34.8 \%$, which is only about $9.30 \mathrm{~mW}$ due to low reflectance of AlN and the gold plating (reflectance of $16 \%$ for AlN and $38 \%$ for $\mathrm{Au}$ in the deep-UV range). In Figure 3c, the ray-tracing profile for PT-II DUV-LEDs shows that the light output will be reduced by $13 \%$ to $8.04 \mathrm{~mW}$ through the flat type quartz plate. We found that even though we changed the quartz plate from the flat type to the lens type shown in Figure $3 \mathrm{~d}$, the light output cannot be increased significantly, and could only be increased from $8.04 \mathrm{~mW}$ to $8.24 \mathrm{~mW}$, a $2.5 \%$ enhancement. The ray-tracing profile and power simulation results for PT-IV and PT-V DUV-LEDs are shown in Figure 3e,f. It is obvious that the color of the chip is not black, which means that the DUV light generated from the chip exits easily. Compared to the PT-I DUV-LED, the light output was improved by $17.0 \%$ for PT-IV and by $70.6 \%$ for PT-V due to the silicone oil inside the cavity. Comparing the different packages with and without silicone oil, we found that the light output power was enhanced by $35.3 \%$ from $8.04 \mathrm{~mW}$ to $10.88 \mathrm{~mW}$ for the flat type (PT-II and PT-IV) and by $92.6 \%$ from $8.24 \mathrm{~mW}$ to $15.87 \mathrm{~mW}$ for the lens type (PT-III and PT-V). This light extraction enhancement is attributed to the reduction of TIR loss. There was no encapsulation layer between the chip and the quartz plate for the conventional DUV-LED structure, thus the DUV light was trapped in the chip. The simulation results showed that the light output could be significantly improved using this liquid type structure, especially for the lens type DUV-LED. 
Table 1. Optical parameters of the components of the proposed DUV-LED.

\begin{tabular}{cc}
\hline Component & Optical Parameters \\
\hline Chip & $\begin{array}{c}\text { Refractive index: } 1.82 \text { for sapphire [15] } \\
\text { Surface: Fresnel loss }\end{array}$ \\
\hline Substrate & Reflectance: $16 \%$ for AlN surface \\
& Reflectance: $38 \%$ for Au surface \\
\hline \multirow{2}{*}{ Quartz } & Refractive index: $1.492[19] ;$ \\
& Transmittance: $95 \%$ @ $10 \mathrm{~mm}$ \\
Surface: Fresnel loss \\
\hline Silicone oil & Refractive index: 1.487 \\
& Transmittance: $94 \%$ @ $10 \mathrm{~mm}$ \\
& Surface: Fresnel loss \\
\hline
\end{tabular}

(a)
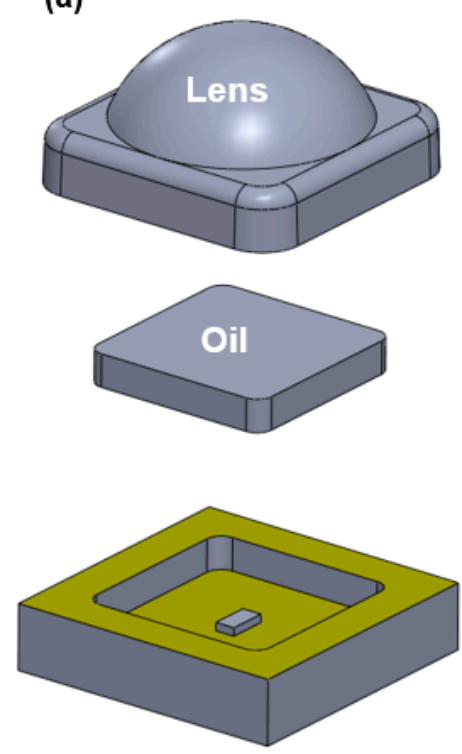

(b) PT-I $9.30 \mathrm{~mW}$

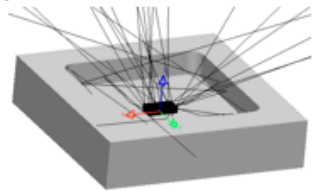

(c) PT-II $8.04 \mathrm{~mW}$

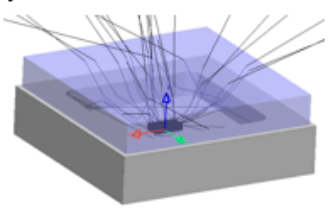

(e) PT-IV $10.88 \mathrm{~mW}$

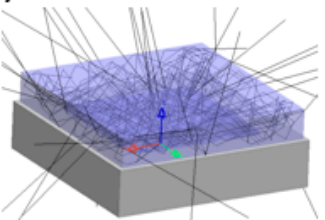

(d) PT-III $8.24 \mathrm{~mW}$

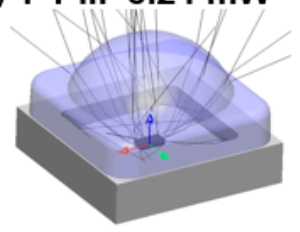

(f) PT-V $15.87 \mathrm{~mW}$

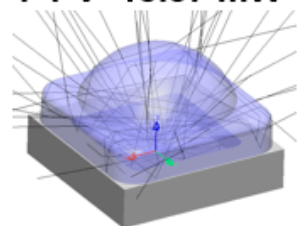

Figure 3. (a) 3D model for the simulation, and the simulation results for the output power for (b) PT-I, (c) PT-II, (d) PT-III, (e) PT-IV, and (f) PT-V DUV-LEDs.

\section{Experiment and Results}

\subsection{Fabrication}

The packaging process of the proposed DUV-LED is illustrated in Figure 4. First, we prepared a ceramic substrate whose electrode and reflectance material are gold, see Figure $4 \mathrm{a}$. Second, we bonded the peak wavelength $281 \mathrm{~nm}$ DUV-LED chip to the ceramic substrate using a soldering bonding process, as shown in Figure 4b. Additionally, the bonding picture of the $281 \mathrm{~nm}, 250 \times 500 \mu \mathrm{m}$ DUV-LED chips is also illustrated in Figure $4 \mathrm{~b}$. Then, we filled the silicone oil (part number: KF-96-50CS, Shin-Etsu Chemical Co., Ltd., Japan) into the cavity, see Figure 4c. After that, in Figure 4 d we placed and sealed the flat type quartz plate onto the substrate with the sealing condition at $80^{\circ} \mathrm{C}$ for 30 minutes. The lens type of the DUV-LEDs in Figure 4e was prepared the same way. 


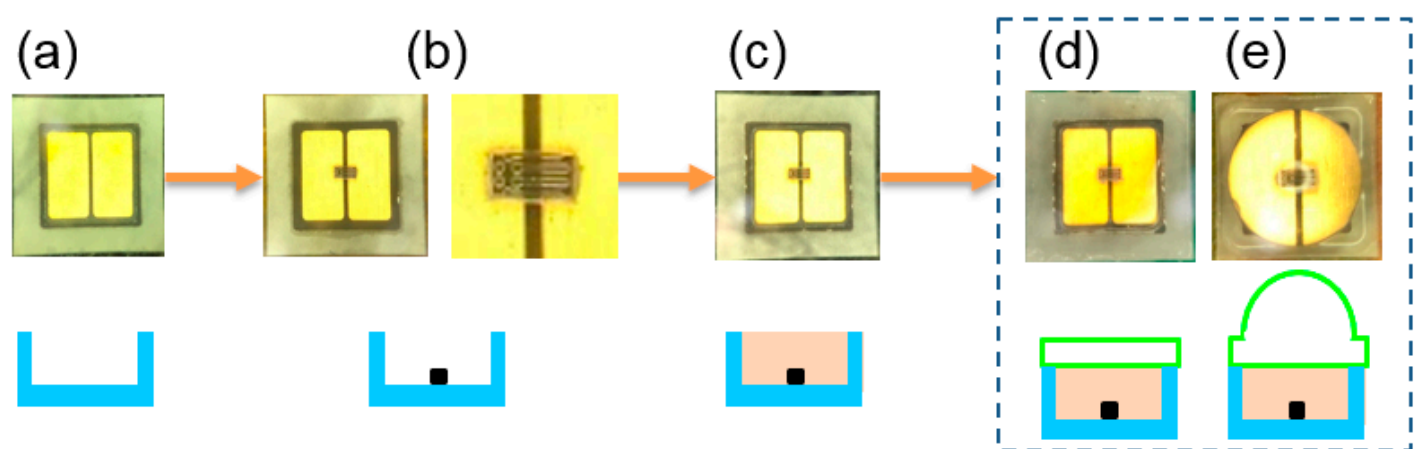

Figure 4. Packaging process of the liquid-package PT-IV and PT-V DUV-LEDs.

\subsection{Optical Measurement Results}

In this part, we tested the optical performance of three different wavelength chips $(281 \mathrm{~nm}, 268 \mathrm{~nm}$, and $310 \mathrm{~nm}$ ) in five different package structures, described in Figure 1. The chip layout and spectrum at $60 \mathrm{~mA}$ for three different wavelength chips are shown in Figure 5. These chips were all flip chip type and their sizes were $250 \times 500 \mu \mathrm{m}, 760 \times 760 \mu \mathrm{m}$, and $500 \times 500 \mu \mathrm{m}$ for $281 \mathrm{~nm}, 268 \mathrm{~nm}$, and $310 \mathrm{~nm}$.
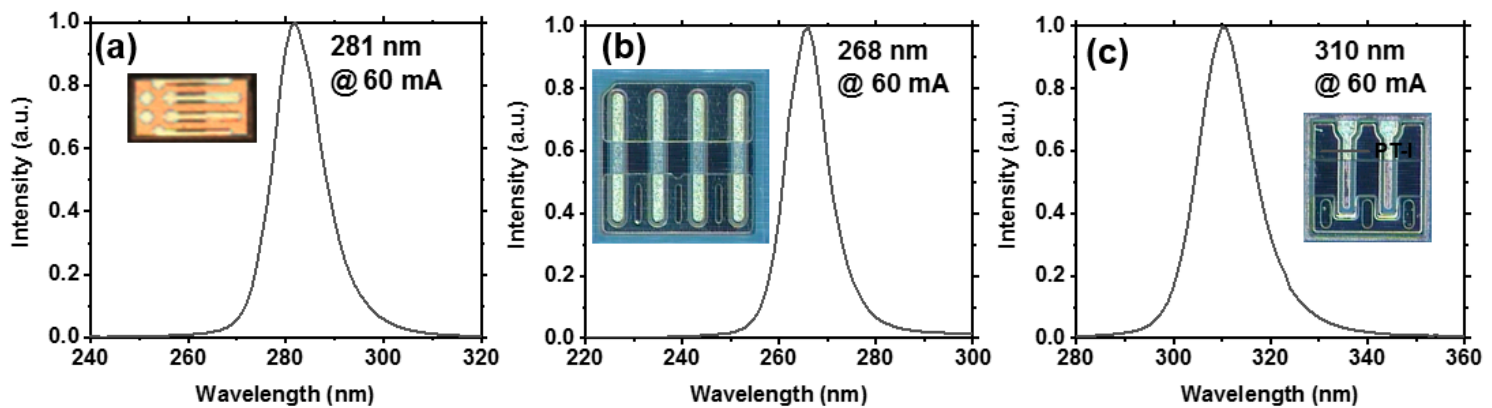

Figure 5. Three different wavelength DUV-LEDs and their spectra at $60 \mathrm{~mA}$.

The results for the optical power of the five PT DUV-LEDs were measured using an integration optoelectronic testing system (model name: 58158S, Chroma, New Taipei City, Taiwan) and are shown in Figure 6 and Table 2. The results showed that using the conventional package methods, the optical power of $9.30 \mathrm{~mW}$ (PT-I) was reduced by $15.1 \%$ to $7.90 \mathrm{~mW}$ for PT-II, and by $10.2 \%$ to $8.35 \mathrm{~mW}$ at $60 \mathrm{~mA}$ for the PT-III DUV-LEDs. With silicone oil inside the cavity, the light output was significantly enhanced, especially for the lens type structure (PT-V). For the flat type structure, from PT-II to PT-IV, the light output was increased by $27.2 \%$, from $7.90 \mathrm{~mW}$ to $10.05 \mathrm{~mW}$ at $60 \mathrm{~mA}$. For the lens type structure, from PT-III to PT-V, the light output was increased by $70.7 \%$, from $8.35 \mathrm{~mW}$ to $14.25 \mathrm{~mW}$ at $60 \mathrm{~mA}$. The measurement results showed the same trend as the simulation results described above.

Table 2. Optical power and EQE results for different types and different wavelength DUV LEDs at $60 \mathrm{~mA}$.

\begin{tabular}{ccccccc}
\hline \multirow{2}{*}{ Packagetype } & \multicolumn{2}{c}{$\mathbf{2 8 1} \mathbf{n m}$} & \multicolumn{2}{c}{$\mathbf{2 6 8} \mathbf{n m}$} & \multicolumn{2}{c}{$\mathbf{3 1 0} \mathbf{n m}$} \\
\cline { 2 - 6 } & Power (mW) & EQE (\%) & Power (mW) & EQE (\%) & Power (mW) & EQE (\%) \\
\hline PT-I & 9.30 & 3.52 & 6.28 & 2.26 & 10.84 & 4.52 \\
PT-II & 7.90 & 2.99 & 5.06 & 1.82 & 9.56 & 3.98 \\
PT-III & 8.35 & 3.17 & 5.30 & 1.90 & 9.88 & 4.12 \\
PT-IV & 10.05 & 3.81 & 6.50 & 2.34 & 11.96 & 4.98 \\
PT-V & 14.25 & 5.39 & 8.68 & 3.12 & 16.52 & 6.89 \\
\hline
\end{tabular}




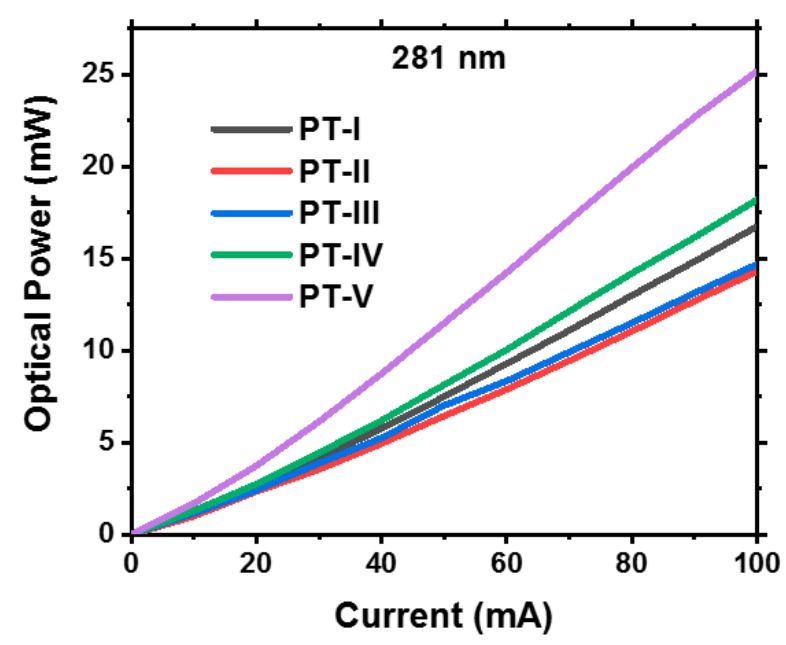

Figure 6. Optical power of $281 \mathrm{~nm}$ five PT DUV-LEDs.

The light improvement effect at different wavelengths, such as $268 \mathrm{~nm}$ and $310 \mathrm{~nm}$, was also tested. The light output results for $268 \mathrm{~nm}$ and $310 \mathrm{~nm}$ are shown in Figure 7 and Table 2. Similar result to those for $281 \mathrm{~nm}$ were observed. For $268 \mathrm{~nm}$, we used a $760 \times 760 \mu \mathrm{m}$ flip chip as the light source. Figure 7a shows that the conventional structure of a $268 \mathrm{~nm}$ DUV-LED, regardless of whether it had a flat type or a lens type quartz, the light output of $6.28 \mathrm{~mW}$ would be reduced by $19.4 \%$ to $5.06 \mathrm{~mW}$ and by $15.6 \%$ to $5.30 \mathrm{~mW}$ at $60 \mathrm{~mA}$, respectively. With silicone oil inside the cavity, for the flat type structure the light output was increased by $28.5 \%$, from $5.06 \mathrm{~mW}$ to $6.05 \mathrm{~mW}$ at $60 \mathrm{~mA}$. For the lens type structure, the light output was increased by $63.8 \%$, from $5.30 \mathrm{~mW}$ to $8.68 \mathrm{~mW}$ at $60 \mathrm{~mA}$. For $310 \mathrm{~nm}$, we used a $500 \times 500 \mu \mathrm{m}$ flip chip as the light source. Figure $7 \mathrm{~b}$ showed that the conventional structure, regardless of whether it has a flat type or a lens type quartz, the light output of $10.84 \mathrm{~mW}$ was reduced by $11.8 \%$ to $9.56 \mathrm{~mW}$ and by $8.9 \%$ to $9.88 \mathrm{~mW}$ at $60 \mathrm{~mA}$, respectively. With silicone oil inside the cavity, for the flat type structure the light output was increased by $25.1 \%$, from $9.56 \mathrm{~mW}$ to $11.96 \mathrm{~mW}$ at $60 \mathrm{~mA}$. For lens type structure, the light output was increased by $67.2 \%$, from $9.88 \mathrm{~mW}$ to $16.52 \mathrm{~mW}$ at $60 \mathrm{~mA}$. The light output and EQE results for the different wavelength and different structure are presented in Table 2. The enhancement ratio of the liquid packaging DUV-LED compared with a DUV-LED without a quartz plate on the top increased with the increased wavelength. This might be due to the transmittance and reflectance of all the components in the DUV-LED package, such as the AIN sidewall, gold plating, quartz plate, and silicone oil, which increase with the increasing wavelength.
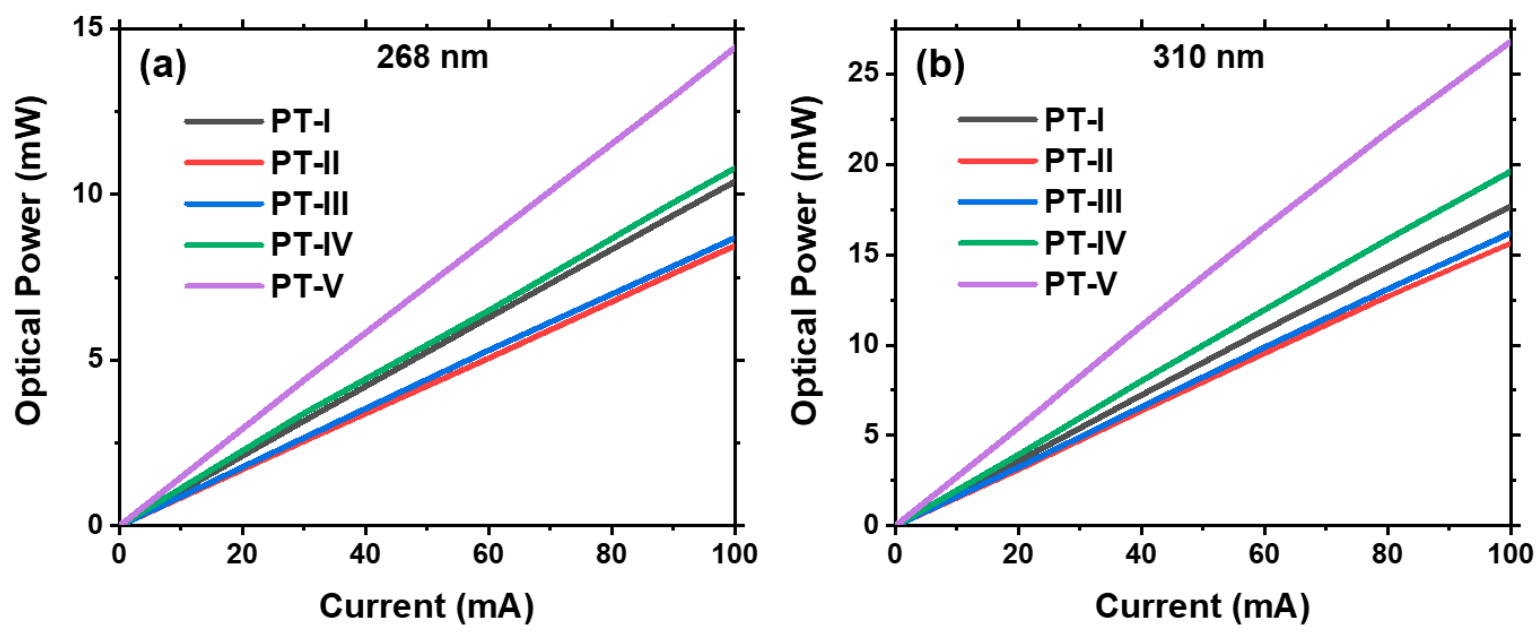

Figure 7. Optical power of the five PTs for (a) $268 \mathrm{~nm}$ and (b) $310 \mathrm{~nm}$ DUV-LEDs. 


\subsection{Thermal Resistance Measurement Result}

As the PT-V showed the best optical performance, the PT-V and its counterpart the PT-III were the focus of the following research.

Some papers have shown that there is great potential for the use of silicone oil as a heat transfer material [20-22]. Some studies have shown that the reduction of thermal resistance could be up to $30 \%$ [22] using a liquid type structure for UVA LED. Since the EQE of DUV-LEDs is still low, the thermal management of DUV-LEDs is very important. The thermal resistance of liquid packaging DUV-LEDs was also measured using a T3Ster system (Mentor, USA), and the results are shown in Figure 8. The thermal resistance of the conventional structure of the $281 \mathrm{~nm}$ DUV-LED package was $28.98 \mathrm{~K} / \mathrm{W}$, as shown in Figure 8a. The thermal resistance of the liquid packaging structure of the $281 \mathrm{~nm}$ DUV-LED package was $20.21 \mathrm{~K} / \mathrm{W}$, as shown in Figure $8 \mathrm{~b}$. The reduction of the thermal resistance using the liquid packaging structure was 30.3\%, which is very similar to previous work [22]. Thermal resistance reduction due to silicone oil was also observed for the DUV-LED package in this study. Referring to the heat dissipation mechanism of the liquid packaging from the previous study [23], the major route of the heat generated from the chip was not through the top of the LED package, thus a comparison of the thermal resistance for the flat type and lens type was not carried out here, and only the DUV-LED package with or without silicone oil was discussed.
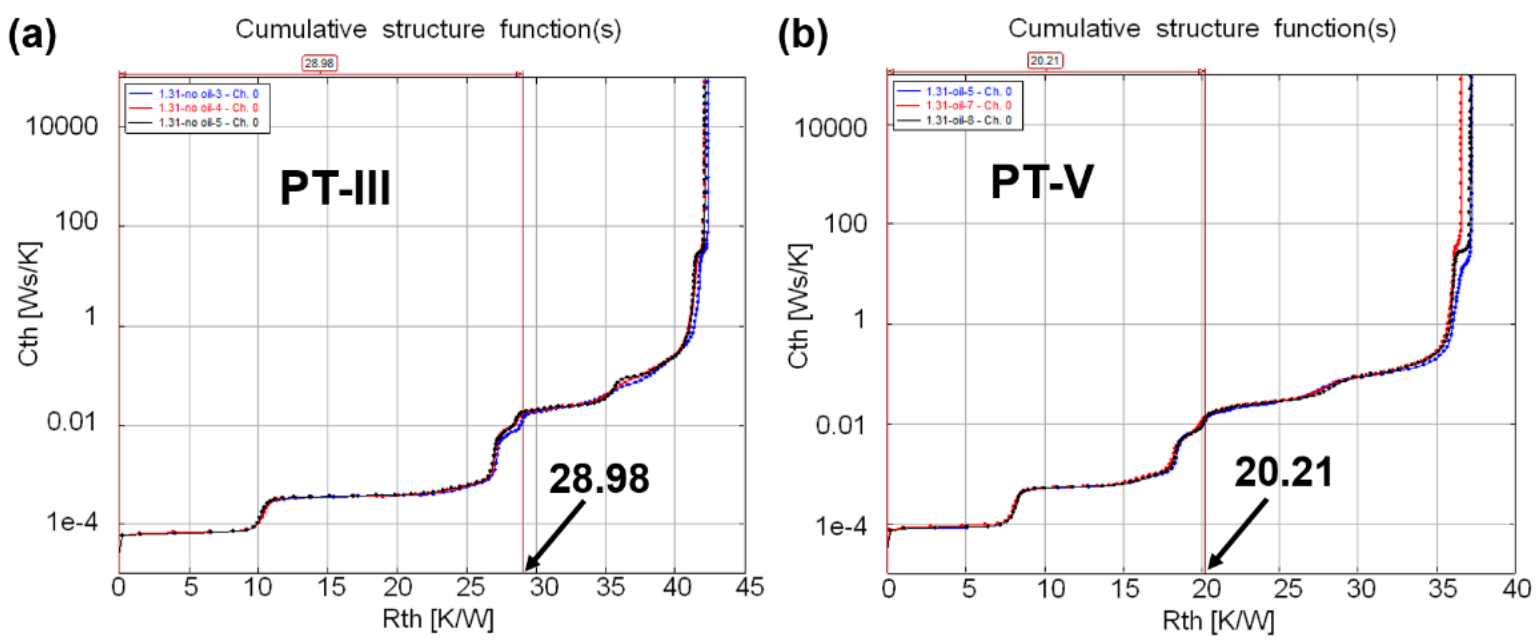

Figure 8. The thermal resistance for $281 \mathrm{~nm}$ (a) PT-III and (b) PT-V DUV-LEDs.

\subsection{Reliability Test Results}

The light maintenance of the $281 \mathrm{~nm}$ liquid packaging DUV-LEDs for 200 hours was tested, and the results are shown in Figure 9. PT-V-Max, PT-V-Avg, and PT-V-Min represent the maximum, average, and minimum value of the light maintenance of the liquid packaging PT-V DUV-LED, respectively. PT-III-Max, PT-III-Avg, and PT-III-Min represent the maximum, average, and minimum value of the light maintenance of the conventional PT-III DUV-LED, respectively. We tested five samples for each PT-III and PT-V DUV-LED to compare the reliability results with and without the liquid packaging design. The test environment was at room temperature of $25^{\circ} \mathrm{C}$ and the driving current was $60 \mathrm{~mA}$. The result shows that the average light maintenance of the liquid packaging DUV-LED and conventional DUV-LED was $98.5 \%$ and $96.6 \%$, respectively. The light maintenance of both structures was at the same level, and the liquid packaging PT-V DUV-LED performed better than conventional one. This implies mass production possibilities for this liquid packaging PT-V DUV-LED. 


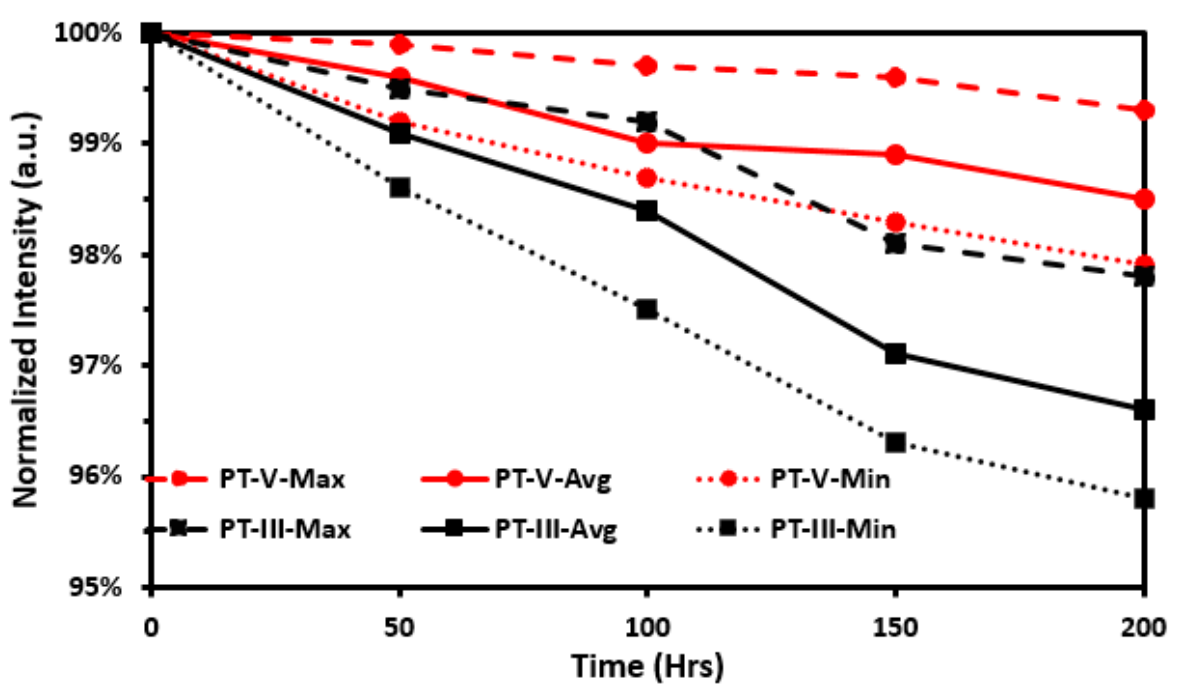

Figure 9. Reliability test results for $281 \mathrm{~nm}$ PT-III and PT-V DUV-LEDs.

\section{Conclusions}

In this study, we introduced a simple fabrication method to improve the light output power of DUV-LEDs. Using silicone oil as the encapsulation material for DUV-LED packages, its process was very similar to that of white light emitting diodes. This increases the possibility of a wide range of DUV-LED applications. Due to the low EQE of DUV-LEDs, enhancing their light output and reducing thermal resistance is very crucial. In this study, we compared the optical power of different package designs with and without silicone oil inside the cavity. For the flat type and lens type package structures, the optical power and EQE were significantly enhanced by $27.2 \%$ and $70.7 \%$ for $281 \mathrm{~nm}$ DUV-LED, respectively. This liquid packaging structure was also workable for $265 \mathrm{~nm}$ and $310 \mathrm{~nm}$ DUV-LEDs. With silicone oil inside the cavity, the optical power and EQE for $268 \mathrm{~nm}$ and $310 \mathrm{~nm}$ were improved by $28.5 \%$ and $25.1 \%$ for the flat type, and by $63.8 \%$ and $67.2 \%$ for the lens type, respectively. Furthermore, using the liquid packaging structure, the thermal resistance was reduced by $30.3 \%$ compared to the conventional structure. The 200-hour reliability test showed that the liquid packaging DUV-LEDs had good thermal and DUV resistance. The proposed liquid packaging structure is feasible as a compact structure with high light extraction efficiency and promising good thermal management of DUV-LED packaging, and it may inspire new packaging structures and methods for DUV-LED devices.

Author Contributions: Supervision, T.W. and H.-C.K.; writing-original draft preparation, C.-Y.K. and C.-H.L.; project administration, P.-T.L. and Z.C.

Funding: Ministry of Science and Technology, Taiwan (MOST) (MOST 105-2221-E-009-112-MY3, 107-2221-E-009113-MY3, and 107-2221-E-009-114-MY3). Strait Postdoctoral Foundation of Fujian Province of China.

Acknowledgments: The authors would like to thank Nakamura Shuji of University of California, Santa Barbara and Hedeto Mayate of Mie University for the helpful discussion.

Conflicts of Interest: The authors declare that there are no conflicts of interest related to this article.

\section{References}

1. Muramoto, Y.; Kimura, M.; Nouda, S. Development and future of ultraviolet light-emitting diodes: UV-LED will replace the UV lamp. Semicond. Sci. Technol. 2014, 29, 084004. [CrossRef]

2. Chen, J.; Loeb, S.; Kim, J.-H. LED revolution: fundamentals and prospects for UV disinfection applications. Environ. Sci.-Wat. Res. 2017, 3, 188-202. [CrossRef]

3. Shin, J.Y.; Kim, S.J.; Kim, D.K.; Kang, D.H. Fundamental Characteristics of Deep-UV Light-Emitting Diodes and Their Application to Control Foodborne Pathogens. Appl. Environ. Microbiol. 2016, 82, 2-10. [CrossRef]

4. Hirayama, H.; Maeda, N.; Fujikawa, S.; Toyoda, S.; Kamata, N. Recent progress and future prospects of AlGaN-based high-efficiency deep-ultraviolet light-emitting diodes. Jpn. J. Appl. Phys. 2014, 53, 100209. [CrossRef] 
5. Inoue, S.I.; Tamari, N.; Taniguchi, M. $150 \mathrm{~mW}$ deep-ultraviolet light-emitting diodes with large-area AlN nanophotonic light-extraction structure emitting at 265nm. Appl. Phys. Lett. 2017, 110, 141106. [CrossRef]

6. De Santi, C.; Meneghini, M.; Monti, D.; Glaab, J.; Guttmann, M.; Rass, J.; Einfeldt, S.; Mehnke, F.; Enslin, J.; Wernicke, T.; et al. Recombination mechanisms and thermal droop in AlGaN-based UV-B LEDs. Photonics Res. 2017, 5, A44-A51. [CrossRef]

7. Fujioka, A.; Asada, K.; Yamada, H.; Ohtsuka, T.; Ogawa, T.; Kosugi, T.; Kishikawa, D.; Mukai, T. High-output-power 255/280/310 nm deep ultraviolet light-emitting diodes and their lifetime characteristics. Semicond. Sci. Technol. 2014, 29, 084005. [CrossRef]

8. Inoue, S.; Naoki, T.; Kinoshita, T.; Obata, T.; Yanagi, H. Light extraction enhancement of $265 \mathrm{~nm}$ deep-ultraviolet light-emitting diodes with over $90 \mathrm{~mW}$ output power via an AlN hybrid nanostructure. Appl. Phys. Lett. 2015, 106, 131104. [CrossRef]

9. Lu, C.-C.; Wang, C.-P.; Liu, C.-Y.; Hsu, C.-P. The Efficiency and Reliability Improvement by Utilizing Quartz Airtight Packaging of UVC LEDs. IEEE T. Electron Dev. 2016, 63, 3143-3146. [CrossRef]

10. Bae, J.-Y.; Kim, Y.; Kim, H.; Kim, Y.; Jin, J.; Bae, B.-S. Ultraviolet Light Stable and Transparent Sol-Gel Methyl Siloxane Hybrid Material for UV Light-Emitting Diode (UV LED) Encapsulant. ACS Appl. Mater. Interfaces 2015, 7, 1035-1039. [CrossRef]

11. Peng, Y.; Wang, S.; Cheng, H.; Chen, M. Whole Inorganic Hermetic Packaging Technology Using Localized Induction Heating for Deep Ultraviolet Light-Emitting Diodes. IEEE T. Comp. Pack. Man. 2016, 6, 1456-1461. [CrossRef]

12. Yamada, K.; Furusawan, Y.; Nagai, S.; Hirano, A.; Ippommatsu, M.; Aosaki, K.; Morishima, N.; Amano, H.; Akasaki, I. Development of underfilling and encapsulation for deep-ultraviolet LEDs. Appl. Phys. Express 2015, 8, 012101. [CrossRef]

13. Nagai, S.; Yamada, K.; Hirano, A.; Ippommatsu, M.; Ito, M.; Morishima, N.; Aosaki, K.; Honda, Y.; Amano, H.; Akasaki, I. Development of highly durable deep-ultraviolet AlGaN-based LED multichip array with hemispherical encapsulated structures using a selected resin through a detailed feasibility study. Jpn. J. Appl. Phys. 2016, 55, 082101. [CrossRef]

14. Peng, Y.; Guo, X.; Liang, R.; Cheng, H.; Chen, M. Enhanced Light Extraction From DUV-LEDs by AlN-Doped Fluoropolymer Encapsulation. IEEE Photonic. Tech. L. 2017, 29, 1151-1154. [CrossRef]

15. Malitson, I.H. Refraction and dispersion of synthetic sapphire. J. Opt. Soc. Am. 1962, 52, 1377-1379. [CrossRef]

16. Schneider, F.; Draheirn, J.; Kamberger, R.; Wallrabe, U. Process and material properties of polydimethylsiloxane (PDMS) for Optical MEMS. Sensor. Actuat. A-Phys. 2009, 151, 95-99. [CrossRef]

17. Khan, M.A. AlGaN multiple quantum well based deep UV LEDs and their applications. Phys. Status Solidi A 2006, 203, 1764-1770. [CrossRef]

18. Kneissl, M.; Kolbe, T.; Chua, C.; Kueller, V.; Lobo, N.; Stellmach, J.; Knauer, A.; Rodriguez, H.; Einfeldt, S.; Yang, Z.; et al. Advances in group III-nitride-based deep UV light-emitting diode technology. Semicond. Sci. Technol. 2011, 26, 014036. [CrossRef]

19. Malitson, I.H. Interspecimen comparison of the refractive index of fused silica. J. Opt. Soc. Am. 1965, 55, 1205-1209. [CrossRef]

20. Xin, G.C.; Wang, Y.P.; Sun, Y.; Huang, Q.W.; Zhu, L. Experimental study of liquid-immersion III-V multi-junction solar cells with dimethyl silicon oil under high concentrations. Energ. Convers. Manage. 2015, 94, 169-177. [CrossRef]

21. Han, X.Y.; Wang, Y.P.; Zhu, L. The performance and long-term stability of silicon concentrator solar cells immersed in dielectric liquids. Energ. Convers. Manage. 2013, 66, 189-198. [CrossRef]

22. Zhang, W.H.; Lin, W.K.; Yeh, C.T.; Chiang, S.B.; Jao, C.S. A novel liquid-packaging technology for highly reliable UV-LED encapsulation. Heat Transf. Res. 2019, 50, 349-360. [CrossRef]

23. Yang, K.S.; Chung, C.H.; Tu, C.W.; Wong, C.C.; Yang, T.Y.; Lee, M.T. Thermal spreading resistance characteristics of a high power light emitting diode module. Appl. Therm. Eng. 2014, 70, 361-368. [CrossRef]

(C) 2019 by the authors. Licensee MDPI, Basel, Switzerland. This article is an open access article distributed under the terms and conditions of the Creative Commons Attribution (CC BY) license (http://creativecommons.org/licenses/by/4.0/). 